\title{
Posterior Epidural Herniation of a Lumbar Disk Fragment at L2-3 That Mimicked an Epidural Hematoma
}

\section{Jin-Sang Kil, Jong-Tae Park}

Department of Neurosurgery, Institute of Wonkwang Medical Science, Wonkwang University School of Medicine \& Hospital Iksan, Korea

\section{Corresponding Author: \\ Jong-Tae Park \\ Department of Neurosurgery, Wonkwang University School of Medicine \& Hospital, 895 Muwang-ro, Iksan 54538, Korea \\ Tel: +82-63-859-1460 \\ Fax: +82-63-852-2606 \\ E-mail: jtpark@wku.ac.kr}

Received: August 25, 2017

Revised: September 22, 2017

Accepted: September 22, 2017
Copyright (C 2017 by The Korean Spinal Neurosurgery Society

This is an open access article distributed under the terms of the Creative Commons Attribution Non-Commercial License (http://creativecommons.org/licenses/bync/4.0/) which permits unrestricted noncommercial use, distribution, and reproduction in any medium, provided the original work is properly cited.

Lumbar disk herniation is common. Because of the posterior longitudinal ligament, migration usually occurs into the ventral epidural space. Rarely, fragments migrate into the dorsal epidural space. A 57-year-old man presented with lower back pain and weakness on right hip flexion and right knee flexion. He had lower back pain 1 day previously and received a transforaminal epidural block at a local hospital. The next day, he reported weakness of the right lower extremity. Lumbar spine magnetic resonance imaging revealed a dorsal epidural lesion with compression of the thecal sac at L2-3. Initial differential diagnoses included epidural hematoma after the block, neoplasm, and a sequestrated disk. Posterior lumbar decompression was performed. The lesion was identified intraoperatively as a large herniated disk fragment. Posterior epidural herniation of a lumbar disk fragment is rare and may be difficult to diagnose preoperatively. It may present as a variety of clinical scenarios and, as in this case, may mimic epidural hematoma.

Key Words: Intervertebral disc, Herniation, Epidural space, Epidural Hematoma

\section{INTRODUCTION}

Herniation of nucleus pulposus derived from disk degeneration is frequent. Disk fragments generally migrate to the anterior epidural space, which is well-defined and delimited by the posterior longitudinal ligament (PLL) and the attached lateral membranes ${ }^{8)}$. Therefore, posterior epidural herniation of a lumbar disk fragment is rare. Only few cases have been repor$\operatorname{ted}^{1,10)}$. The posterior epidural herniation of a disk fragment have a similarity to tumor, hematoma, and abscess on radiological assesment $t^{5,7}$. Therefore, differential diagnosis of this condition may be difficult.

Here, we report a case of posterior epidural herniation of a lumbar disk fragment at L2-3. The lesion showed unusual radiographic findings and the patient had a past history, so it mimicked an epidural hematoma.

\section{CASE REPORT}

The patient was a 57-year-old man who presented with lower back pain and weakness on right hip flexion and right knee flexion. $\mathrm{He}$ had lower back pain 1 day previously, and received a transforaminal epidural block at L2-3 at a local hospital. He had taken 100-mg aspirin and antihypertensive drugs for 3 years due to a previous infarction and essential hypertension. The next day, he reported weakness of the right lower extremity. After walking 10 steps, he sat down due to weakness of the right lower extremity.

In our hospital, a neurologic examination was performed. The motor power in right hip flexion and right knee flexion was $4 / 5$. Sensation in the lower extremity was intact. Other neurologic examination was not shown abnormalities. Magnetic resonance imaging (MRI) of the lumbar spine revealed a dorsal epidural lesion with compression of the thecal sac at L2-3. The lesion had relative hypointensity on T2weighted imaging and isointensity on T1-weighted imaging (Fig. 1). We did not perform enhancement MRI. In blood test, erythrocyte sedimentation rate was $3.0 \mathrm{~mm} / \mathrm{hr}$ and a C-reactive protein level was $0.29 \mathrm{mg} / \mathrm{L}$. The result showed that the chances of infection were highly unlikely. Prothrombin time and activated partial thromboplastin time were not prolonged (9.9 seconds; 26.1 secodns). Bleeding time was not assessed. The initial differential diagnoses included epidural hematoma after the block, tumor, and a sequestrated disk. Operation was performed. We used laminectomy at $\mathrm{L} 2$ via posterior approach. After removal of the ligamentum flavum, a large, solid posterior epidural herniation of disk fragment was identified. The fragment compressed thecal sac, anteriorly (Fig. 2). Granulation tissue was identified 


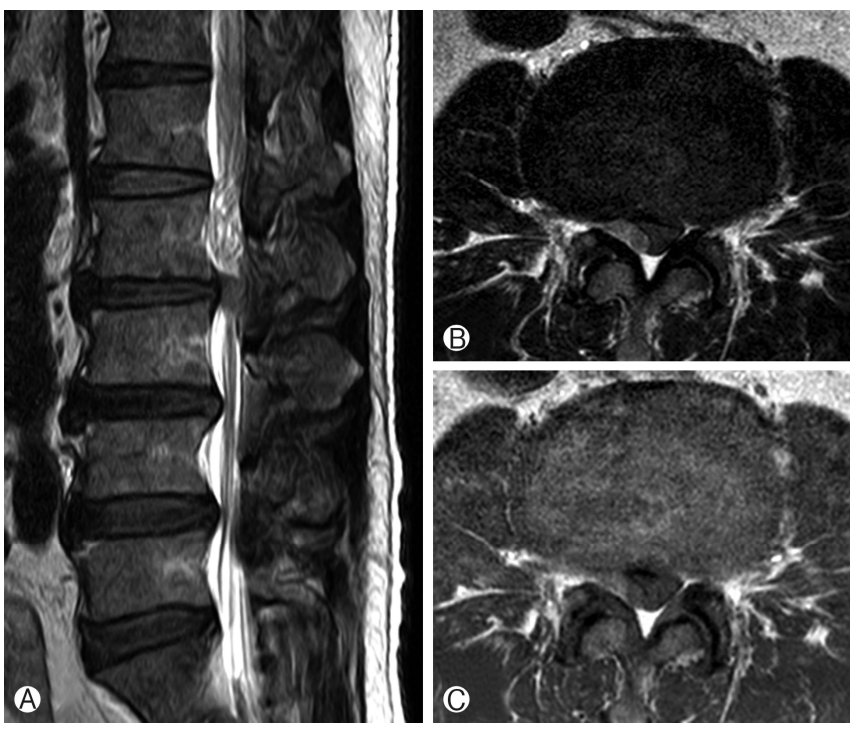

Fig. 1. (A) A sagittal T2-weighted magnetic resonance imaging (MRI) of the lumbar spine shows a hypointense epidural mass at the L2-3 level. (B) An axial T2-weighted MRI shows a hypointense epidural mass, compressing the thecal sac. (C) An axial T1-weighted MRI shows an isointense epidural mass, compressing the thecal sac.

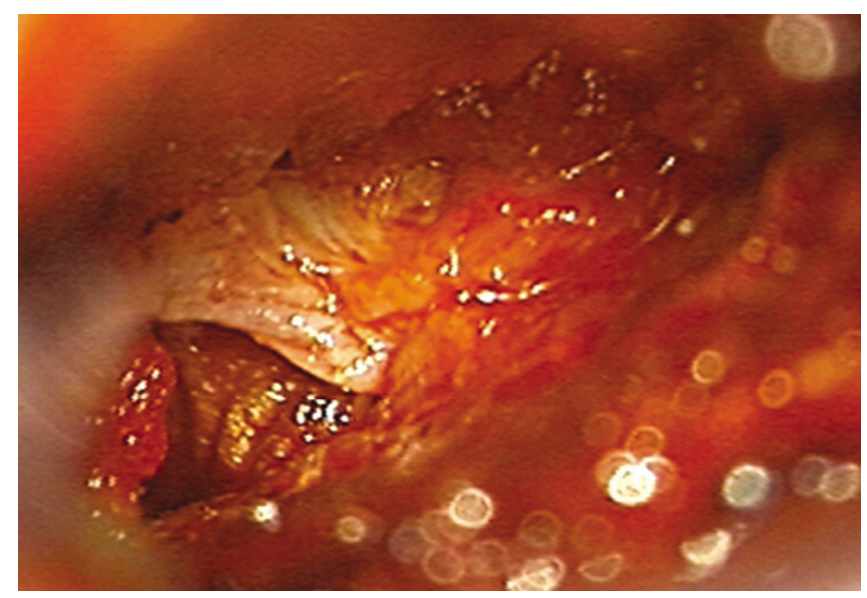

Fig. 2. Intraoperative photograph showing posterior migration of the herniated disc. After removal of the ligamentum flavum, a large, solid posterior epidural herniation of disk fragment was identified. The fragment compressed thecal sac, anteriorly.

around the disk fragment. After removal of the fragment, we identified an annular defect of the disk space. The specimen was determined to be fresh, degenerated fibrocartilage on histopathologic analysis. The postoperative course was uneventful. After 2 weeks of physiotherapy, the patient's right lower extremity weakness resolved.

\section{DISCUSSION}

Posterior epidural herniation of lumbar disk fragments is rare. The disk fragment migrations are commonly limited by the at- tachments of the PLL and its associated midline septum and peridural or lateral membrane, and the nerve root itself ${ }^{1,2)}$. The disk fragments are usually relocated in the anterior epidural space; they are infrequently found lateral to the thecal sac. Cephalad migration is more common with lateral disk herniation, whereas caudal displacement may be more common in central disk herniation $^{3)}$. The pathogenic mechanism of posterior epidural herniation of lumbar disk fragment was not understood. Maybe, a problem with anatomical barriers, such as PLL, causes posterior epidural herniation of lumbar disk fragment.

The symptoms of posterior epidural herniation of lumbar disk fragment are variable and include lumbago and cauda equina syndrome ${ }^{4)}$. Our patient presented with lower back pain and weakness on right hip flexion and right knee flexion. There were no sensory changes, bladder dysfunction, or bowel problems.

The differential diagnosis of posterior epidural herniation of lumbar disk fragments may be difficult. MRI was the method of choice for radiological diagnosis of lumbar degenerative diseases. However, it was hard to differentiate completely similar lesions such as herniated disk, epidural hematoma, tumor or abscess $^{10)}$.

Herniated disks are usually hypointense on T1-weighted images and hyperintense on $80 \%$ of T2-weighted images ${ }^{1,2)}$. The high signal intensity on T2-weighted images is because the herniated substance still has a higher water content compared to an unbroken disk, or may be due to a reparative course leading to a temporary water increase ${ }^{6}$. In our patient, the lesion was located in the posterior epidural space. The lesion had relative hypointensity on T2-weighted imaging and isointensity on T1-weighted imaging.

The differential diagnosis between posterior epidural herniation of lumbar disk fragment and epidural hematoma is very difficult. Disc herniation with migration may have contact with the disk space from which the fragment arised, whereas hematomas have lesser contact with a disk space ${ }^{9)}$. In our patient, the lesion did not show continuity with a disk space on MRI. Intraoperatively, we identified an annular defect of the disk space. Epidural hematomas are associated with a history of trauma. Our patient had taken antiplatelet drugs. He received a transforaminal epidural block at L2-3 before symptom onset. In a variety of these situations, the lesion mimics an epidural hematoma.

Early surgery is the first choice for treatment. Generally, the surgical outcome of posterior epidural herniation of a lumbar disk fragment is better than conventional disk herniation ${ }^{1,2)}$. Our patient's surgical outcome was also good.

\section{CONCLUSION}

Posterior epidural herniation of lumbar disk fragment is rare and difficult to diagnose, as it may mimic other, more common posterior epidural lesions. Posterior epidural herniation of lumbar disk fragment should be considered in the differential diagnosis of dorsal epidural lesions. Surgical treatment should be considered for the best outcome. 


\section{CONFLICT OF INTEREST}

No potential conflict of interest relevant to this article was reported.

\section{REFERENCES}

1. Akhaddar A, El-Asri A, Boucetta M: Posterior epidural migration of a lumbar disc fragment: a series of 6 cases. J Neurosurg Spine 15:117-128, 2011

2. Dösoğlu M, Is M, Gezen F, Ziyal MI: Posterior epidural migration of a lumbar disc fragment causing cauda equina syndrome: case report and review of the relevant literature. Eur Spine J 10:348-351, 2001

3. Ebeling U, Reulen HJ: Are there typical localisations of lumbar disc herniations? A prospective study. Acta Neurochir (Wien) 117: 143-148, 1992

4. Eysel P, Herbsthofer B: Dorsal compression of the epidural cord due to free sequestral lumbar prolapse. Diagnostic problems in mag- netic resonance imaging and computed tomography. Arch Orthop Trauma Surg 121:238-240, 2001

5. Lakshmanan P, Ahuja S, Lyons K, Howes J, Davies PR: Sequestrated lumbar intervertebral disc in the posterior epidural space: a report on two cases and review of the literature. Spine J 6:583-586, 2006

6. Masaryk TJ, Ross JS, Modic MT, Boumphrey F, Bohlman H, Wilber G: High-resolution MR imaging of sequestered lumbar intervertebral disks. AJR Am J Roentgenol 150:1155-1162, 1988

7. Robe P, Martin D, Lenelle J, Stevenaert A: Posterior epidural migration of sequestered lumbar disc fragments. Report of two cases. J Neurosurg 90(2 Suppl):264-266, 1999

8. Schellinger D, Manz HJ, Vidic B, Patronas NJ, Deveikis JP, Muraki AS, et al: Disk fragment migration. Radiology 175:831-836, 1990

9. Tarukado K, Ikuta K, Fukutoku Y, Tono O, Doi T: Spontaneous regression of posterior epidural migrated lumbar disc fragments: case series. Spine J 15:e57-62, 2015

10. Teufack SG, Singh H, Harrop J, Ratliff J: Dorsal epidural intervertebral disk herniation with atypical radiographic findings: case report and literature review. J Spinal Cord Med 33:268-271, 2010 